\title{
A Comparative Study to Evaluate the Efficacy of Butorphanol as an Adjuvant to Epidural Analgesia for Rib Fractures
}

\author{
${ }^{1}$ Virendrakumar R Belekar, ${ }^{2}$ Vaibhav Jain
}

\begin{abstract}
Introduction: Pain management via epidural catheters have emerged as an optimal method of pain control in patients with rib fractures (RF). This study was done to evaluate the efficacy of butorphanol in this subset of patients.
\end{abstract}

Materials and methods: Sixty patients were randomly allocated in two groups R (ropivacaine only) and B (ropivacaine with butorphanol). Group $\mathrm{R}$ patients received $0.2 \%$ ropivacaine epidurally $(10 \mathrm{~mL}$ ) while group B patients received $0.2 \%$ ropivacaine and $1 \mathrm{mg}$ butorphanol epidurally $(10 \mathrm{~mL})$. Baseline respiratory rate, oxygen saturation, partial pressure of oxygen $(\mathrm{PaO} 2)$, visual analog score (VAS), peak inspiratory flow rate (PIFR) were noted in both the groups.

Results: There was significant increase in duration of analgesia and nonsignificant reduction in VAS score in group B, and nonsignificant decrease in invasive ventilation cases and significant reduction in length of intensive care unit (ICU) stay in group B. There were no significant adverse effects in both the groups except for nausea in group $B$.

Conclusion: Butorphanol as an adjuvant to epidural analgesia leads to better oxygenation, decrease in length of ICU stay and duration of mechanical ventilation without increase in significant side effects.

Keywords: Butorphanol, Epidural analgesia, Rib fracture, Ropivacaine.

How to cite this article: Belekar VR, Jain V. A Comparative Study to Evaluate the Efficacy of Butorphanol as an Adjuvant to Epidural Analgesia for Rib Fractures. Int J Recent Surg Med Sci 2017;3(2):93-97.

\section{Source of support: Nil}

Conflict of interest: None

\section{INTRODUCTION}

Rib fractures associated with road traffic accidents are significant cause of morbidity and mortality. Despite continued progress in therapeutic interventions, RFs

\footnotetext{
${ }^{1}$ Associate Professor, ${ }^{2}$ Consultant

${ }^{1}$ Department of Anesthesia, Jawaharlal Nehru Medical College Wardha, Maharashtra, India

${ }^{2}$ Department of Anesthesia, Shriram Hospital, Jodhpur Rajasthan, India

Corresponding Author: Virendrakumar R Belekar, Associate Professor, Department of Anesthesia, Jawaharlal Nehru Medical College, Wardha, Maharashtra, India, Phone: +919970164680 e-mail: vbelekar@gmail.com
}

continue to be associated with significant adverse sequelae, including diminished ventilatory effort, atelectasis, pneumonia, longer hospital and ICU lengths of stay, and higher mortality. ${ }^{1-5}$ Increases in RF-related morbidity and mortality parallel the increasing number of RFs. ${ }^{3} \mathrm{Rib}$ fractures leads to respiratory complications. ${ }^{1,2,5}$

The treatment for injuries of the bony thorax has varied over the years ranging from mechanical stabilization through obligatory ventilator support. Adequate pain control, chest physiotherapy, and mobilization are recommended for the chest trauma. Failure of this regimen and ensuing mechanical ventilation set the stage for progressive respiratory morbidity and mortality.

Pain due to rib fractures can be treated with epidural analges. Newer drugs with better safety profile have been added to anesthesiologist's armamentarium for pain control via epidural route. Epidural catheter placement is associated with a significantly decreased risk of dying in patients with blunt thoracic injury of three or more RFs. ${ }^{6}$ This study was done to evaluate the efficacy of butorphanol in this subset of patients.

\section{MATERIALS AND METHODS}

This prospective clinical study was conducted after Institutional Ethics Committee approval in a tertiary care hospital.

\section{Sample Size Calculation}

During routine management, it was observed that ropivacaine with butorphanol provides better and longer duration of analgesia in two-third patients as compared with ropivacaine alone. Therefore, sample size was calculated as expected better analgesia for longer duration in $66 \%$ cases (two-thirds) when ropivacaine was combined with butorphanol. Therefore, using two groups (proportion), we compared the populations using the software IBM Statistical Package for Social Sciences (SPSS) 17.0, Microsoft excel 2013 and formula as below:

$$
\begin{gathered}
\mathrm{n} \text { (patients per group) }=16 \mathrm{PQ} / \mathrm{D}^{2} \\
\text { where } \mathrm{P}=\mathrm{P} 1+\mathrm{P} 2 / 2 \\
\mathrm{Q}=100-\mathrm{P} \\
\mathrm{D}=\mathrm{P} 1-\mathrm{P} 2
\end{gathered}
$$


Therefore, the sample size estimated was 28 patients in each group. So, each group constituted 30 patients.

\section{Inclusion and Exclusion Criteria}

Patients aged 20 to 60 years of either sex with blunt trauma chest with three or more consecutive RFs were included.

Patients with sternal fractures, bilateral RFs flail chest, patients who were intubated, with any contraindication to epidural catheterization and comorbid conditions, such as hypertension, heart disease, obstructive pulmonary disease were excluded from the study. This study comprised 60 patients with RFs admitted to surgical intensive care unit (SICU) from July 2011 to December 2014. They were randomly allocated to two groups using computergenerated codes.

Out of total 140 patients admitted to SICU with RFs, 70 patients had associated major organ injury and traumatic brain injury, 6 patients were managed with oral medications, and 4 patients had less than three RF.

Of the total 60 patients, 30 patients having three or more RFs were included in the study with or without any other major organ injury including traumatic brain injury. All the 60 patients enrolled in the study had history of trauma within 3 hours of admission to the SICU. Patients were assigned to either of two groups. After initial evaluation, epidural catheter was introduced by the trained anesthesiologist within 1 hour of the SICU admission. With all aseptic precautions, $18 \mathrm{G}$ Tuohy epidural needle was introduced in lateral position two space below the level of fractured ribs and space was identified using loss of resistance to saline. Tip of epidural catheter was secured at the level of fractured rib.

Group R (ropivacaine group) included 30 patients and received $0.2 \%$ ropivacaine epidurally $(10 \mathrm{~mL})$ while group $\mathrm{B}$ (butorphanol with ropivacaine) included 30 patients who

Table 1: Clinical parameters

\begin{tabular}{lllll}
\hline & & Group $R$ & Group B & p-value \\
\hline RR Mean & Pretest & $38.21 \pm 2.12$ & $38.12 \pm 2.01$ & $0.56 \mathrm{NS}$ \\
$(\mathrm{SD})$ & Posttest & $24.39 \pm 3.21$ & $20.63 \pm 1.23$ & $0.043 \mathrm{~S}$ \\
& p-value & $0.002 \mathrm{~S}$ & $0.005 \mathrm{~S}$ & \\
$\mathrm{PaO}_{2}$ Mean & Pretest & $54.32 \pm 3.12$ & $55.32 \pm 1.32$ & $0.65 \mathrm{NS}$ \\
$(\mathrm{SD})$ & Posttest & $88.69 \pm 2.23$ & $87.52 \pm 1.45$ & $0.61 \mathrm{NS}$ \\
& p-value & $0.001 \mathrm{~S}$ & $0.003 \mathrm{~S}$ & \\
VAS Mean & Pretest & $8.31 \pm 2.15$ & $8.65 \pm 2.26$ & $0.71 \mathrm{NS}$ \\
(SD) & Posttest & $4.65 \pm 2.32$ & $3.39 \pm 2.31$ & $0.06 \mathrm{NS}$ \\
& p-value & $0.0003 \mathrm{~S}$ & $0.0002 \mathrm{~S}$ & \\
P/F ratio & Pretest & $121.23 \pm 1.32$ & $121.31 \pm 3.51$ & $0.61 \mathrm{NS}$ \\
& Posttest & $202.32 \pm 1.53$ & $205.31 \pm 2.12$ & $0.56 \mathrm{NS}$ \\
& p-value & $0.0001 \mathrm{~S}$ & $0.0002 \mathrm{~S}$ & \\
PIFR Mean & Pretest & $299.51 \pm 1.01$ & $298.32 \pm 1.32$ & $0.72 \mathrm{NS}$ \\
(SD) & Posttest & $451.23 \pm 1.21$ & $450.21 \pm 1.21$ & $0.61 \mathrm{NS}$ \\
& p-value & $0.0001 \mathrm{~S}$ & $0.0003 \mathrm{~S}$ & \\
\hline
\end{tabular}

SD: Standard deviation; S: Significant; NS: Nonsignificant received $0.2 \%$ ropivacaine and $1 \mathrm{mg}$ butorphanol epidurally $(10 \mathrm{~mL})$. Baseline respiratory rate, oxygen saturation, $\mathrm{PaO}_{2}$, VAS, and PIFR were noted in both the groups.

Patients were assessed by the Staff nurse trained in pain clinic for more than 3 years and study drug was administered when the VAS score was $>4$. Pain-free duration of analgesia was noted (patient in VAS score less than 4). Arterial blood gas was done after study drug administration and $\mathrm{PaO} 2$ was noted. $\mathrm{FiO}_{2}$ was variable for each patient. Hence $\mathrm{P} / \mathrm{F}$ ratio was used to standardize the variable.

Complications like nausea, vomiting, bradycardia, hypoventilation, hypotension, and any others were noted in both the groups. Mean respiratory rate, duration of analgesia, mean VAS score, Ramsay sedation scale score, mean PIFR, length of ICU stay, incidence of mechanical ventilation, and mortality were all noted and compared statistically.

\section{Statistical Analysis}

Clinical parameters and demographic variables (Table 1) were analyzed using paired t-test. Sedation score, duration of analgesia, and number of doses were analyzed (Table 2) by Student's t-test. Mortality and number of patients requiring mechanical ventilation were analyzed by chi-square test (Table 3). Student's t-test was used to analyze length of ICU stay in two groups. Side effects in two groups were compared by chi-square test (Table 4).

\section{RESULTS}

\section{Demographic Profile}

Out of 140 patients admitted to the SICU with RFs, 80 patients were excluded; 70 patients had associated

Table 2: Patient analgesia and sedation

\begin{tabular}{llll}
\hline & Group R & Group B & \\
\hline $\begin{array}{l}\text { Mean duration of } \\
\text { analgesia (min) }\end{array}$ & $240.21 \pm 2.21$ & $280.32 \pm 1.23$ & $0.012 \mathrm{~S}$ \\
$\begin{array}{l}\text { Ramsay sedation } \\
\text { scale Score (Mean) }\end{array}$ & $2.01 \pm 1.01$ & $2.75 \pm 1.05$ & $0.043 \mathrm{~S}$ \\
$\begin{array}{l}\text { Mean number of } \\
\text { doses per day }\end{array}$ & $5.32 \pm 1.21$ & $4.65 \pm 1.07$ & $0.035 \mathrm{~S}$ \\
\hline S: Significant & & & \\
\hline
\end{tabular}

Table 3: Other parameters

\begin{tabular}{lllll}
\hline & & Group R & Group B & Significance \\
\hline Mechanical ventilation & NIV & 3 & 3 & $1.00 \mathrm{NS}$ \\
& IV & 5 & 4 & $0.83 \mathrm{NS}$ \\
Mortality & & 1 & 1 & $1.00 \mathrm{NS}$ \\
Length of ICU stay in & & 8 & 6 & $0.049 \mathrm{~S}$
\end{tabular}

days

S: Significant; NS: Nonsignificant: NIV; Non-invasive ventilation; IV; Invasive ventilation 


\begin{tabular}{llll}
\hline \multicolumn{4}{c}{ Table 4: Adverse effects } \\
\hline Group R & Group B & Significance \\
\hline Hypotension & 6 & 8 & $0.54 \mathrm{NS}$ \\
Bradycardia & 2 & 2 & $1.00 \mathrm{NS}$ \\
Nausea & 5 & 10 & $0.041 \mathrm{~S}$ \\
Vomiting & 4 & 6 & $0.053 \mathrm{NS}$ \\
Urinary retention & 3 & 4 & $0.063 \mathrm{NS}$ \\
\hline S: Significant; NS: Nonsignificant &
\end{tabular}

major organ injury and traumatic brain injury, 6 patients were managed with oral medications, and 4 patients had less than three RFs. Sixty patients were enrolled in the study and divided into two groups (groups R and B) of thirty each. The two groups did not differ in terms of age, gender, weight ( $p>0.05)$. Both the groups were identical in terms of number of RFs ( $\mathrm{p}>0.05)$.

Table 1 shows clinical parameters in the two groups The mean baseline variables [respiratory rate (RR), $\mathrm{PaO}_{2}, \mathrm{VAS}, \mathrm{P} / \mathrm{F}$ ratio and PIFR] in both the groups were comparable and not statistically significant $(\mathrm{p}>0.05)$.

- The posttest decrease in mean RR was significantly lower in both the groups as compared with their respective pretest values $(p<0.05)$. However, the decrease in group $B$ was significantly more than in group $\mathrm{R}(\mathrm{p}<0.05)$.

- The posttest increase in mean $\mathrm{PaO}_{2}$ was significant in both the groups as compared with their respective pretest values $(\mathrm{p}<0.05)$ and was comparable to each other $(\mathrm{p}>0.05)$.

- The posttest decrease in mean VAS was significant in both the groups as compared with their respective pretest values $(p<0.05)$ and was comparable to each other $(\mathrm{p}>0.05)$.

- The posttest increase in mean $\mathrm{P} / \mathrm{F}$ ratio was significant in both the groups as compared with their respective pretest values $(p<0.05)$ and was comparable to each other $(\mathrm{p}>0.05)$.

- The posttest increase in mean PIFR was significant in both the groups as compared with their respective pretest values $(p<0.05)$ and was comparable to each other $(\mathrm{p}>0.05)$.

Table 2 shows characteristics of patient analgesia and sedation

The mean duration of analgesia was significantly higher in group $\mathrm{B}$ as compared with group $\mathrm{R}(\mathrm{p}<0.05)$.

The mean Ramsay sedation scale score was significantly more in group $B$ as compared with group $R(p<0.05)$.

Group $B$ required significantly less number of rescue analgesics per day as compared with group $\mathrm{R}(\mathrm{p}<0.05)$.

Other parameters (Table 3) like incidence of mechanical ventilation and mortality were comparable in both the groups and were statistically nonsignificant $(p>0.05)$. Mean and SD for length of ICU stay.
Though less number of patients required invasive ventilation in group $B$, the difference was not significant $(\mathrm{p}>0.05)$.

Length of ICU stay was significantly less in group B as compared with group $\mathrm{R}(\mathrm{p}<0.05)$.

Incidence of adverse effects (Table 4 ) was same in both the groups and was statistically nonsignificant $(p>0.05)$ except for nausea, which was significantly higher in group B $(p<0.05)$. Severity was not assessed. Only the complaint of nauseous feeling was noted.

\section{DISCUSSION}

Blunt trauma chest remains a significant cause of morbidity and mortality in the present world associated with high-speed vehicular accidents, with as many as $25 \%$ deaths attributable to thoracic injuries. ${ }^{78}$ Rib fractures are associated with increased morbidity and mortality due to resultant associated pain. Severe pain leads to splinting of respiratory muscles resulting in respiratory dysfunction. Respiratory dysfunction causes atelectasis, impaired clearance of respiratory secretions, impaired cough leading to hypoxemia, increased shunt, pulmonary infections, and requirement of mechanical ventilatory support. ${ }^{9,10}$ Keeping in mind this association of pain due to RFs and pulmonary complications, lot of research has been done to determine the safety and the efficacy of different analgesic techniques and pharmacotherapy.

Epidural analgesia using local anesthetic agents has been proven to be better than systemic opioid analgesics in providing thoracotomy pain management. ${ }^{11-13}$ Though systematic review and a meta-analysis of randomized controlled trials of epidural analgesia in adult patients with traumatic RFs found no significant benefit on mortality, ICU, and hospital length of stay compared with other analgesic modalities, ${ }^{14}$ improved pain management using epidural analgesia in patients with RFs was associated with improved vital capacity and improved inspiratory and expiratory flow rates and better outcome. ${ }^{9,10}$ Epidural analgesia increases the patients' compliance and cooperation for pulmonary toileting, thereby improving pulmonary functions and decreasing pulmonary complication. ${ }^{15}$

We studied the effect of epidural analgesia with local anesthetic agent, ropivacaine with and without opioid, and butorphanol in patients with chest wall injuries. Ropivacaine has a greater degree of motor sensory differentiation, which is desirable in patients with RFs where analgesia is of prime importance and motor blockade is undesirable. Moreover, it is also associated with decreased potential for central nervous system toxicity and cardiotoxicity. ${ }^{16}$ Butorphanol, a lipid-soluble narcotic, has strong analgesic and sedative properties 
without respiratory depression. Butorphanol has been frequently used for postoperative analgesia and labor analgesia. When compared with more potent narcotics like fentanyl, epidural butorphanol provides significantly prolonged analgesia with minimum cardiorespiratory side effects. ${ }^{17}$

Till date, various investigators have compared epidural analgesia with systemic opioids, epidural local anesthetic agents (bupivacaine) with or without adjuvants. ${ }^{17,18}$ However, no study has been done to study the efficacy of epidural butorphanol and ropivacaine in these subjects as mentioned earlier.

Demographic profile and patient characteristics with respect to number of unilateral/bilateral RFs were comparable in both the groups and were found statistically nonsignificant $(\mathrm{p}>0.05)$.

In our study, we found that there was significant increase in duration of analgesia and nonsignificant reduction in VAS score in group $\mathrm{B}$, which was associated with better compliance for deep breathing exercises, better vital capacity, and nonsignificant decrease in invasive ventilation cases (four in group $\mathrm{B}$ vs five in group $\mathrm{R}$ ) and significant reduction in length of ICU stay in group $B$.

Epidural analgesia has been shown to increase functional residual volume, lung capacity compliance, vital capacity, decreased airway resistance, and increased $\mathrm{PaO}_{2}$. Patients remain awake and cooperate with pulmonary toileting ${ }^{13}$ and chest physiotherapy. These were apparent in patients of this study as well.

Dittmann in his series of articles on pain management in blunt trauma chest showed that intubation and positive pressure ventilation can be avoided in patients using epidural analgesia and can be managed on spontaneous breathing. Similar results were shown by various investigators using local anesthetics with or without morphine through epidural catheters. ${ }^{15,20}$

Though the Ramsay sedation scale scores were significantly more in group B, no patients required airway intervention and were responsive to the verbal commands.

There was significant increase in $\mathrm{PaO} 2, \mathrm{P} / \mathrm{F}$ ratios, and PIFR in both the groups, but degree of increase in two groups was comparable and nonsignificant. Several small studies have been conducted wherein it was observed that epidural analgesia with opioid adjuvant improves vital capacity, oxygenation, and PIFRs and reduces pulmonary complications. ${ }^{19}$

Epidural analgesia is associated with various complications; on comparing the adverse effects in both groups, we found hypotension, bradycardia, nausea, vomiting, and urinary retention in both the groups. Number of patients having hypotension (eight in group B vs six in group $\mathrm{R}$ ) and vomiting (six in group $\mathrm{B}$ vs four in group $\mathrm{R}$ ), urinary retention (four in group $\mathrm{B} v$ s three in group $\mathrm{R}$ ).
These incidents were more in group $B$ than in group $R$, but the difference was nonsignificant $(p>0.05)$.

Hypotension was corrected by intravenous (IV) fluids and no patient in any group required vasopressors. Vomiting was treated with ondansetron $0.1 \mathrm{mg} / \mathrm{kg}$. Urinary retention was treated with urinary catheterization which was removed after draining the urine. Significant number of patients had nausea in group B than group R. All the adverse effects were attributable to epidural analgesia, which was augmented by addition of butorphanol in group B. No patient in any group had serious complications associated with epidural analgesia like dural puncture, neurological injury, epidural hematoma, infection, accidental subarachnoid injection with its serious consequences, and local anesthetic toxicity associated with accidental IV injection. Mortality in both the groups was comparable and was nonsignificant.

Use of epidural analgesia requires epidural catheters, which adds up to overall cost of hospital stay which is detrimental in developing countries, primarily in rural setups. Improved survival, decreased length of ICU stay, and decreased requirement of mechanical ventilation will effectively bring down the cost of hospital care.

\section{LIMITATIONS OF THE STUDY}

There was no evaluation on the effect of epidural analgesia on physiotherapy and incidence of nosocomial pneumonia. Patient-controlled analgesia and other analgesic techniques, such as nonopioid analgesics, nerve blocks are also available modalities of treatment for pain management in thoracic and RFs, which were not evaluated and compared with epidural analgesia. Except for epidural analgesia, other analgesic techniques were out of scope of the present study. Additionally, further research is needed into clinical pathways that take into account the mechanism of action and pain pathways. Multicentric study with larger sample size is suggested to evaluate the effect of epidural analgesia with the various other analgesic modalities in clinical practice.

\section{CONCLUSION}

The advantages of epidural analgesia with local analgesics have been well established in patients with RFs as reflected by improvements in VAS scores, inspiratory flow rates, oxygenation, and pulmonary compliance and reduced pulmonary complications.

\section{TAKE-HOME MESSAGE}

Butorphanol as an adjuvant in epidurral analgesia can be be used to improve the quality of analgesia without any major side effects. 


\section{REFERENCES}

1. Bulger EM, Edwards T, Klotz P, Jurkovich GJ. Epidural analgesia improves outcome after multiple rib fractures. Surgery 2004 Aug;136(2):426-430.

2. Kieninger AN, Bair HA, Bendick PJ, Howells GA. Epidural versus intravenous pain control in elderly patients with rib fractures. Am J Surg 2005 Mar;189(3):327-330.

3. Stawicki SP, Grossman MD, Hoey BA, Miller DL, Reed JF 3rd. Rib fractures in the elderly: a marker of injury severity. J Am Geriatr Soc 2004 May;52(5):805-808.

4. Wisner DH. A stepwise logistic regression analysis of factors affecting morbidity and mortality after thoracic trauma: effect of epidural analgesia. J Trauma 1990 Jul;30(7):799-804.

5. Wu CL, Jani ND, Perkins FM, Barquist E. Thoracic epidural analgesia versus intravenous patient controlled analgesia for the treatment of rib fracture pain after motor vehicle crash. J Trauma 1999 Sep;47(3):564-567.

6. Gage A, Rivara F, Wang J, Jurkovich GJ, Arbabi S. The effect of epidural placement in patients after blunt thoracic trauma. J Trauma Acute Care Surg 2014 Jan;76(1):39-45.

7. Moon MR, Luchette FA, Gibson SW, Crews J, Sudarshan G, Hurst JM, Davis K Jr, Johannigman JA. Prospective, randomized comparison of epidural versus parenteral opioid analgesia in thoracic trauma. Ann Surg 1999 May;229(5):684-691.

8. Trunkey DD. Trauma. Accidental and intentional injuries account for more years of life lost in the U.S. than cancer and heart disease. Among the prescribed remedies are improved preventive efforts, speedier surgery and further research. Sci Am 1983 Aug;249(2):28-35.

9. Ullman DA, Fortune JB, Greenhouse BB, Wimpy RE, Kennedy TM. The treatment of patients with multiple rib fractures using continuous thoracic epidural narcotic infusion. Reg Anesth 1989 Jan-Feb;14(1):43-47.

10. Cicala RS, VoellerGR, FoxT,Fabian TC, KudskK, MangianteEC. Epidural analgesia in thoracic trauma: effects of lumbar morphine and thoracic bupivacaine on pulmonary function. Crit Care Med 1990 Feb;18(2):229-231.

11. Shulman M, Sandler AN, Bradley JW, Young PS, Brebner J. Postthoracotomy pain and pulmonary function following epidural and systemic morphine. Anesthesiology 1984 Nov;61(5):569-575.

12. Asantila R, Rosenberg PH, Scheinin B. Comparison of different methods of postoperative analgesia after thoracotomy. Acta Anaesthesiol Scand 1986 Aug;30(6):421-425.

13. Zwarts SJ, Hasenbos MA, Gielen MJ, Kho HG. The effect of continuous epidural analgesia with sufentanil and bupivacaine during and after thoracic surgery on the plasma cortisol concentration and pain relief. Reg Anesth 1989 Jul-Aug; 14(4):183-188.

14. 14. Bruce JS. Pain Management Guidelines for Blunt Thoracic Trauma. J Trauma 2005 Nov; 59(5):1256-1267.

15. Kuthiala G, Chaudhary G. Ropivacaine: A review of its pharmacology and clinical use. Indian J Anaesthesia 2011 Mar-Apr; 55(2):104-110.

16. Kaur J, Bajwa S. Comparison of epidural butorphanol and fentanyl as adjuvants in the lower abdominal surgery: A randomized clinical study. Saudi J Anaesth 2014; 8(2):167-171.

17. Jarvis AM, Cook CH, Lindsey DE, Reilley TE, Steinberg SM, Beery II PR et al. Comparison of epidural versus parenteral analgesia for traumatic rib fractures: a meta-analysis. OPUS 12 scientist 2009;3(3):50-57.

18. Parris R. Epidural analgesia/anaesthesia versus systemic intravenous opioid analgesia in the management of blunt thoracic trauma. 2008.

19. Dittmann M, Ferstl A, Wolff G. Epidural analgesia for the treatment of multiple rib fractures. Europ J Intensive Care Med 1975;1:71-75.

20. Dittmann M, Keller R, Wolff G. A rationale for epidural analgesia in the treatment of multiple rib fractures. Intensive Care Med 1978;4:193-197. 